\title{
Game Theory Analysis of E-Commerce's Price War
}

\author{
Yue Hu, Manzhen Tang \\ Jinan University Management School, Guangzhou, China \\ Email: 406852758@qq.com
}

Received 1 November 2014; revised 30 November 2014; accepted 15 December 2014

Copyright (C) 2014 by author and Scientific Research Publishing Inc.

This work is licensed under the Creative Commons Attribution International License (CC BY). http://creativecommons.org/licenses/by/4.0/

c) (7) Open Access

\begin{abstract}
Home appliance industry is one of the most competitive industries in China, but the price war also prolonged. The reasons for E-commerce price war of home appliance industry are various; this article attempts to use the game theory and information economics analysis method to discuss the form of competition pattern, and further study the possibility of price coordination behavior in the industry. The analysis to our enlightenment is that, in order to get out of the price war trap, and improve the industry competition level, home appliance enterprises must pay more attention to technology and product innovation. At the same time, E-commerce should be rational to marketing strategy; it could avoid market competition environment destruction, and loss of consumer confidence caused by excessive price war in the adverse consequences.
\end{abstract}

\section{Keywords}

Home Appliance Industry, E-Commerce Price War, Nash Equilibrium, Cooperation Win-Win

\section{Introduction}

On August 14, 2012, Liu Dongqiang, the CEO of Jingdong company, posted news in Weibo, and then other senior managers including Suning, Gome responded this Weibo. A new E-commerce price war has begun, as Dangdang, Yixun companies joined in this war, which is finally evolved into a free-for-all of the entire domestic electricity industry's war.

The cause of the E-commerce war, fundamentally, is due to the rapid growth of the home appliance industry, IT industry in our country. In recent years, the development of home appliance industry has a good development, then price war often occurs among the air conditioners, washing machines, microwave ovens and other commodity; the price war almost involves all the home appliance product, and has gradually spread to the main way of sales. Although the rounds of E-commerce price war may eventually became a war of word because of vari- 
ous reasons, it still made home appliance industry hard to get out "price war trap": repetitive price war continued for a long time making all industry manufacturers actively or passively involved, so that the industry were in excessive competition situation [1]. We cannot ignore the butterfly effect behind the price war: a better propaganda or more perfect transformation offline, or lift marketing. However, in terms of the goods itself, excessive price competition could lead enterprise to have no time to research and develop core technology, and then homogeneity competition may make lower industry profits and even deficit. More than ten years, although our country home appliance industry continues to grow, there is not the core competitiveness of industry; industry profit margins are low, generally in the $5 \%$ or less. Therefore, the price wars lead to adverse consequences.

In general, there are many industry's competitive behaviors, such as pricing behavior, advertising practices, and mergers. Pricing is a basic form; it shows the characterization of the enterprise's comprehensive; strength behind the price advantage means the advantages of production costs, technology, economies of scale, value chain, marketing channels and service brand. On the current E-commerce sales (home appliances) situation, the original of the price war is that the price could change relatively wide; price cutting can be successfully achieved [2]. Therefore, pricing plays an important role in the price war. How to price the product, and how to eliminate the negative impact of the price war, are also what we are actively concerned.

Based on the above discussion, we will explore the form of E-commerce price war and how to make home appliances industry to get rid of the plight of the price war trap, which uses game theory and information economics. This article attempts to use the game theory and information economics analysis method to discuss the form of competition pattern, and further study the possibility of price coordination behavior in the industry. The analysis to our enlightenment is that, in order to get out of the price war trap, and improve the industry competition level, home appliance enterprises must pay more attention to technology and product innovation.

\section{From the "Prisoner's Dilemma" to the "Price Game"}

In game theory, the classic "prisoner's dilemma” game can indicate the reasons for the price war broke out. Prisoners are as follows: Police arrest two suspects: A and B, but there is no enough evidence for a conviction. So following the separation of the two men, the police offer them the same choice: If one man betrays his partner, while the other remains silent, the betrays will be immediately released, and the silence will jail for eight years; if two people are silent, they would sentenced to imprisonment for 1 year; if two people at the same time to confess, they would sentenced to imprisonment for five years. The payoff matrix is shown below (see Table 1).

In this case, there are usually two results: cooperative and non-cooperative, cooperative is collective rationality, non-cooperative game assuming rational individual participants, pursuing individual reward. From the matrix of results, we can see when they would get a better reward if they both cooperated. However, due to human selfishness and fear of the other side of betrayal, regardless of what the other decides, each prisoner gets a higher pay-off by betraying the others. Using static games of complete information's scribing method; we can conclude that, the strategy (cooperative, cooperative) is the best strategy for both of them. This is a classic Nash equilibrium [3].

Now, we consider the price war of home appliance. In this war, we first assumed that there are only two oligopolistic firms on the market (considering the Jingdong Mall and Suning, add more oligopolistic firms may analogy analysis), they both sell homogeneous products, and wants to occupy market share in order to earn greater profits. Meanwhile, the game process meets the following two characteristics: 1) Complete Information. The pricing behavior of two companies is public, and also for consumers, competitors can easily get other price information, so it can be considered to be incomplete information; 2) Repeated Game. Both prices are constantly changing, competitor change their price based on the other's price, so it is a repeated game. At the same time, we can see that both sides using only one competitive strategy that is the price competition. The above conditions are met the basic conditions of the complete information repeated game model. Then, we assumed

Table 1. Prisoner's dilemma payoff matrix.

\begin{tabular}{ccc}
\hline & Prisoner B stays silent (cooperates) & Prisoner B stays betray (defects) \\
\hline Prisoner A stayssilent (cooperates) & $(-5,-5)$ & $(0,-8)$ \\
Prisoner A staysbetrays (defects) & $(-8,0)$ & $(-1,-1)$ \\
\hline
\end{tabular}

From: Weiying Zhang (2012), game theory and information economics. 
that, if two companies are taking high-priced policy, each of them can reap the benefits of 100 units; if both cut price, each of them may benefit 70 units; if a company (Jingdong Mall) does not cut price while the other company (Suning) cut prices, so Jingdong Mall obtains 20 units, the Suning obtains 150 units and vice versa. The payoff matrix is shown below (see Table 2).

In order to expand market share, two companies have two choices: keep price or lower price, and repeat it. From the market perspective, the consumers welcome to price competition. It is no exaggeration to say that most consumers like low-priced. Because of the enormous influence of the enterprise market share, price-fixing cartel is no sufficient binding. If one of them began to cut price, it makes price agreements bankruptcy. To purse maximize interests, each company does not have the power to maintain the agreement. This is a rational choice between individual and group, which particularly reflected in the price war.

Price competition oligopoly firms often find themselves in a prisoner's dilemma. If others do not cut price, we use low-priced to capture the market; if others cut price, we must cut too. Although, like a prisoner, all companies know the result of collusion is better, but they worried partner will defaults, so it is easy touch off a large-scale price war [4]. As I said at the start, Jingdong Mall come up with a "zero margins" stunt to increase sales and expand market share. So Suning and Gome have to cut price in order to meet the challenge, thereby they break up the balance of its original price. It makes everyone in this war fall into a price trap (of course, we only consider they cut the price of its terms, except for price war fraud).

\section{Nash Equilibrium and the Price War}

In the traditional prisoner's dilemma, we know that (cooperative, cooperative) is the only Nash equilibrium, while the price of the online retailer for the above game, there is also a unique Nash equilibrium (low-priced, low-priced), which calls sub-game perfect Nash equilibrium strategy. Since the sub-game perfect Nash equilibrium with consensus estimates, that is the actual behavior of each player's choice consistent with their predictions, so the prisoner would choose to be honest, oligopolistic firms will choose low-priced.

We can determine the outcome of the online retailer war is "Nash equilibrium", and it is stable. This result may be benefit to consumers, but to online retailer is disastrou. Therefore, the price war means suicide for online retailer, the result of price-cutting competition could lead to an efficient zero profit outcomes. Every company will consider taking the normal pricing strategy, or taking a low priced strategy to form a monopoly price, and try to get monopoly profits. If the monopoly formed, they both earn the biggest profit. This situation is monopoly usually raise prices. Another extreme case is the online retailers with the normal price, both sides can profit. We can get a basic guideline: "Put your own strategy based on the best interests of their opponents will be assumed on the basis of action". In fact, the perfect competitive equilibrium is the "Nash equilibrium" or "noncooperative game equilibrium". In this state, each online retailer or consumer is in accordance with all of the others have been given price to make decisions. In this equilibrium, each enterprise makes profit maximization, consumer makes utility maximization, it will result in a zero profit, and namely, price equals marginal cost [5].

Under perfect competition, this kind of non-cooperative behavior accords with requirement of economic efficiency. If the online retailer take cooperative action and decided to price at monopoly price, then the economic efficiency of society will be destroyed. This is also the WTO (The World Trade Organization which is deals with the global rules of trade between nations) and various national governments to strengthen antitrust significance.

Above the price war of the online retailer, there is a unique Nash equilibrium, but there may have Multiple Nash equilibrium issues. If we amend the payoff in above price war's matrix according to follow rule: when one retailer choose to cut prices, as consumers hold a certain hope that the others cutting price too, then it leading to low-priced one falling instead of rising profits, so we get follow payoff matrix (see Table 3).

In the above model, there exist two kinds of Nash equilibrium, namely (high-priced, high-priced) and (low-

Table 2. The price war's payoff matrix.

\begin{tabular}{ccc}
\hline & Jingdong Mall (high-priced) & Jingdong Mall (low-priced) \\
\hline Suning (high-priced) & $(100,100)$ & $(20,150)$ \\
Suning (low-priced) & $(150,20)$ & $(70,70)$ \\
\hline
\end{tabular}


Table 3. The price war's payoff matrix (multiple Nash equilibrium).

\begin{tabular}{ccc}
\hline & Jingdong Mall (high-priced) & Jingdong Mall (low-priced) \\
\hline Suning (high-priced) & $(100,100)$ & $(50,80)$ \\
Suning (low-priced) & $(80,50)$ & $(70,70)$ \\
\hline
\end{tabular}

priced, low-priced). Obviously, (high-priced, high-priced) is the better one in the sense of Pareto efficiency significantly, so (high-priced, high-priced) becomes a Pareto efficiency to balance this game. In other words, if two online retailer's decision-makers are rational, then there is no price war between them. Because the best choice depends on the choice of the other in this game, when one choose high-priced that the other do so best, but when the other choice is low-priced, your best choice is high-priced, so each retailer hopes to achieve not only their own (high-priced, high-priced), it also expect the other one will choose a high-priced, so (high-priced, highpriced) should be reasonable result of the game.

From the Nash equilibrium, we can draw a conclusion. Cooperation is the best self-interest strategy, and it must comply with the following principles: a group of players are in Nash equilibrium if each one is making the best decision that he or she can, taking into account the decisions of the others in the game, which is the main emphasis of a collective rationality. Meanwhile, the Nash equilibrium is a non-cooperative game equilibrium, whose research interests are in the situation of mutual influences how the selection strategy can make their greatest profits, it emphasizes the individual rationality.

\section{Game Analysis of Price Coordination Possibilities}

Objectively price cartels are collusion between firms and adjust price action, thereafter the party to the collusion is directly involved in the business. Price coordination is very significant as one of trade associations' governance functions in order to, but it has not been paid attention to in law and got consistency in understanding. As the price collusion often lack of legitimacy, the price coordination between enterprises is not usually has a clear agreement and contract, rather take the form of secret conspiracy. Now, we analysis the possibility of price coordination in the home appliance industry:

Based on the above assumptions and analysis, considering the Prisoner's Dilemma model, under the assumption that the game is repeated endless times, the theoretically proved that if participants have enough patience, (betray, betray) is a Nash equilibrium. Similarly, in the infinitely repeated games, (high-priced, high-priced) is Nash equilibrium in the price war. So we have to consider "grim strategy": 1) start selecting high-priced; 2) Select high-priced until one party chose low-priced, and always choose low. It can be shown grim strategy is a Nash equilibrium: $\eta$ means discount factor (assuming the two companies have the same discount factor). Using above price war model (see Table 2) [6], if Jingdong Mall first select a low-priced at some stage in the game, payoff for this stage is 150 . But this opportunistic behavior will trigger Suning "always select low-priced" as a punishment, so Jingdong Mall earn 70 at a later stage. Therefore, if meet the following conditions, namely Suning does not select low-priced, Jingdong Mall will not select the low-priced.

$$
150+\eta(70)+\eta^{2}(70)+\cdots \leq 100+\eta(100)+\eta^{2}(100)+\cdots
$$

Next: $150+70 \eta /(1-\eta) \leq 100 /(1-\eta)$

Next: $\eta \geq \frac{5}{8}$

Hence, if $\eta \geq \frac{5}{8}$, Suning still choose "grim strategy" and no low-priced first, Jingdong Mall will never choose low-priced first. However, if Suning choose low-priced first and forever, Jingdong Mall will actively insist on choose "grim strategy", and he can earn 70 at a later stage. Otherwise, Jingdong Mall can't earn more than 70 in other strategy. Thus, no matter what $\eta$ is, Jingdong Mall motivated insisted grim strategy. Similarly, grim strategy is a good option for Suning. Therefore, we have proved the grim strategy is Nash equilibrium, and is unique, so it is also a sub-game perfect Nash equilibrium.

Further, we assumed that each participant has the possibility of irrational by $\alpha, 1-\alpha$ is rational, it can 
prove that, company choose low-priced from the outset is not a rational man's best choice under conditions of grim strategy. First considering Suning adopt a low price strategy, if Jingdong Mall first selecting low-priced at $t$ $=1$, exposing themselves as rational people, then, at beginning of $t=2$, they both will choose low price until $T$ (i.e.: $t \geq 2$ ), whereby the maximum expected earnings of Jingdong Mall is:

$$
150+\eta(70)+\eta^{2}(70)+\cdots+\eta^{T}(70)
$$

Think about Jingdong Mall's other strategy: Choose high-priced until the start time T, unless Suning select low-priced in $t$-stage. In this case, the $t+1$ began to select high until $T$. Thus, the maximum expected earnings of Jingdong Mall is:

$$
\alpha \times 100 \times T+\left((1-\alpha)\left[\eta(20)+\eta^{2}(70)+\cdots+\eta^{T-1}(70)+\eta^{T}(70)\right]\right.
$$

If follow condition is satisfied, this strategy is certainly better than the price from the outset selection strategy

$$
\alpha \times 100 \times T+(1-\alpha)\left[\eta(20)+\eta^{2}(70)+\cdots+\eta^{T-1}(70)+\eta^{T}(70)\right]>150+\eta(70)+\eta^{2}(70)+\cdots \eta^{T}(70)
$$

When $\eta$ is known that we can get an interval range of $T>T^{\prime}$, if the time interval is greater than the length of the range, from the outset, we choose low-priced is not rational people (smart people) optimal strategies, no matter how small $\alpha$ is, there is always exists $T^{\prime}$ make all $T>T^{\prime}$, and then it shows that select the price is not rational people's the best choice when in $t=1$. Therefore, for a rational enterprise, taking grim strategy can avoid a price war, as in this case, no one want to take the first or subsequent price reduction strategy.

Price competition cannot take place repeatedly in reality. So, if there is a possibility that enterprises can avoid price wars, reaching win-win results under certain price competitions. The answer is positive if only the times of rivalry are enough. After long-time and tough price wars, it has a probability that those survived giant companies could coordinate the price [7]. And so, in most cases, they prefer to act as "no refutation" or "do not know" etc. For those enterprises, this kind of "nonfeasance” means that Oligopolies can cease the fire of price and enjoy the high profits together, as long as the requirement of cooperation is met. For this reason, price collusion in private could happen very likely. Many countries also adopt such price strategies alike, namely "price alliance” in pursuit of win-win results. Undoubtedly, there are some restrictions between countries. Therefore, it could last a relatively long period of time. In the case of enterprises in the appliance home industry, however, this sort of alliance will ultimately collapse as a result, because of lack of legality as well as stability. Thus, we could conclude that competition is still the mainstream while cooperation takes a back seat considering the current development situation of Chinese appliance home industry and enterprises of it. But, in order to pursuit higher profits, various price collusions will still emerge from the hands of oligopolies as the possibility of price coordination in certain industry exists in reality.

\section{Conclusion}

Price competition is an effective way to make the price in a reasonable level and force enterprises to lower the costs of running companies; it will benefit both the enterprise itself and consumers and in the long run, enhance the efficiency of economic development. Excessive competition, however, could decline the enterprises' benefits. Therefore, in terms of competitors in appliance home industry, they should take positive strategies to avoid trapping themselves in a downward spiral of price war under certain conditions. The strategy which should be adopted depends on the competitors and market situation. Above all, it has to take both the resources that the enterprise owns and its management ability into consideration. If possible, it can unite various ways. Whatever strategy it takes to avoid or go against price war, all the enterprises ultimately have to keep the core-competitiveness in hand, maintaining lasting advantages. Price competition is just a primary stage of market competition and quality, service and innovation play a bigger role in appliance home industry today.

\section{References}

[1] (2012) Documentary of the Price War in Appliance Home Industry on August 15-A War without Smoke of Gunpowder. PC online Exclusive Planning for Digital Home Appliance. http://www.pconline.com.cn/digital/815dsdz/

[2] Ouyang, Y.Y. and Tao, F. (2005) Price War and Coordination of China’s Appliance Home Industry-An Analysis Based on Game Theory. Business's Modernization Academic Edition, 1.

[3] Xie, S.Y. (2008) Economic Game Theory. 3rd Edition, Fudan University Press, Shanghai. 
[4] Zhang, W.Y. (2012) Game Theory and Information Economics. Gezhi Press, Shanghai.

[5] Ye, Y.J. and Li, Q. (2007) Price War's Game Theory Analysis and Strategy. Medium-Sized and Small Enterprises' Science and Technology, $\mathbf{5}$.

[6] Wang, K. and Tang, W.J. (2002) Game Theory Problems in Monopolistic Producers’ Product Pricing-An Simultaneous Comment on the Price War in Chinese Color Tv Industry. Academic Journal of Anhui University (Edition for Philosophy, Society and Science), 1.

[7] Niu, G.Y. (2012) A Game Theory Based Analysis of the Tacit Knowledge Sharing and Incentive Mechanism. Advanced Materials Research, III. 
Scientific Research Publishing (SCIRP) is one of the largest Open Access journal publishers. It is currently publishing more than 200 open access, online, peer-reviewed journals covering a wide range of academic disciplines. SCIRP serves the worldwide academic communities and contributes to the progress and application of science with its publication.

Other selected journals from SCIRP are listed as below. Submit your manuscript to us via either submit@scirp.org or Online Submission Portal.
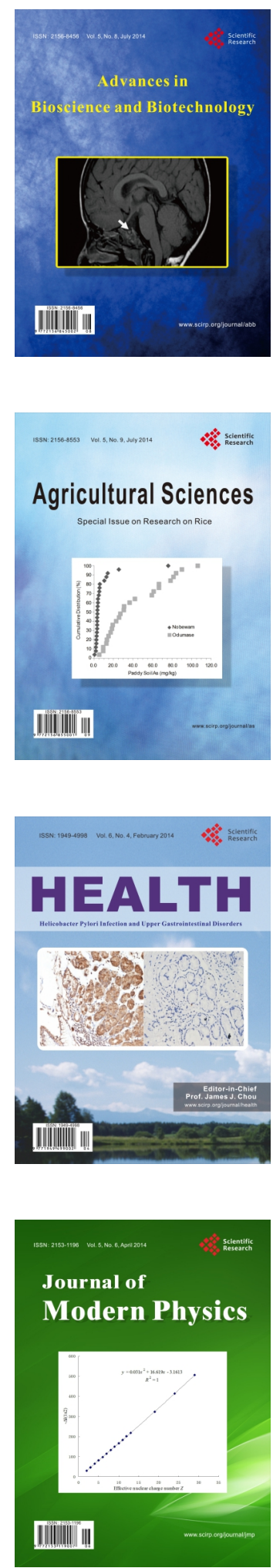
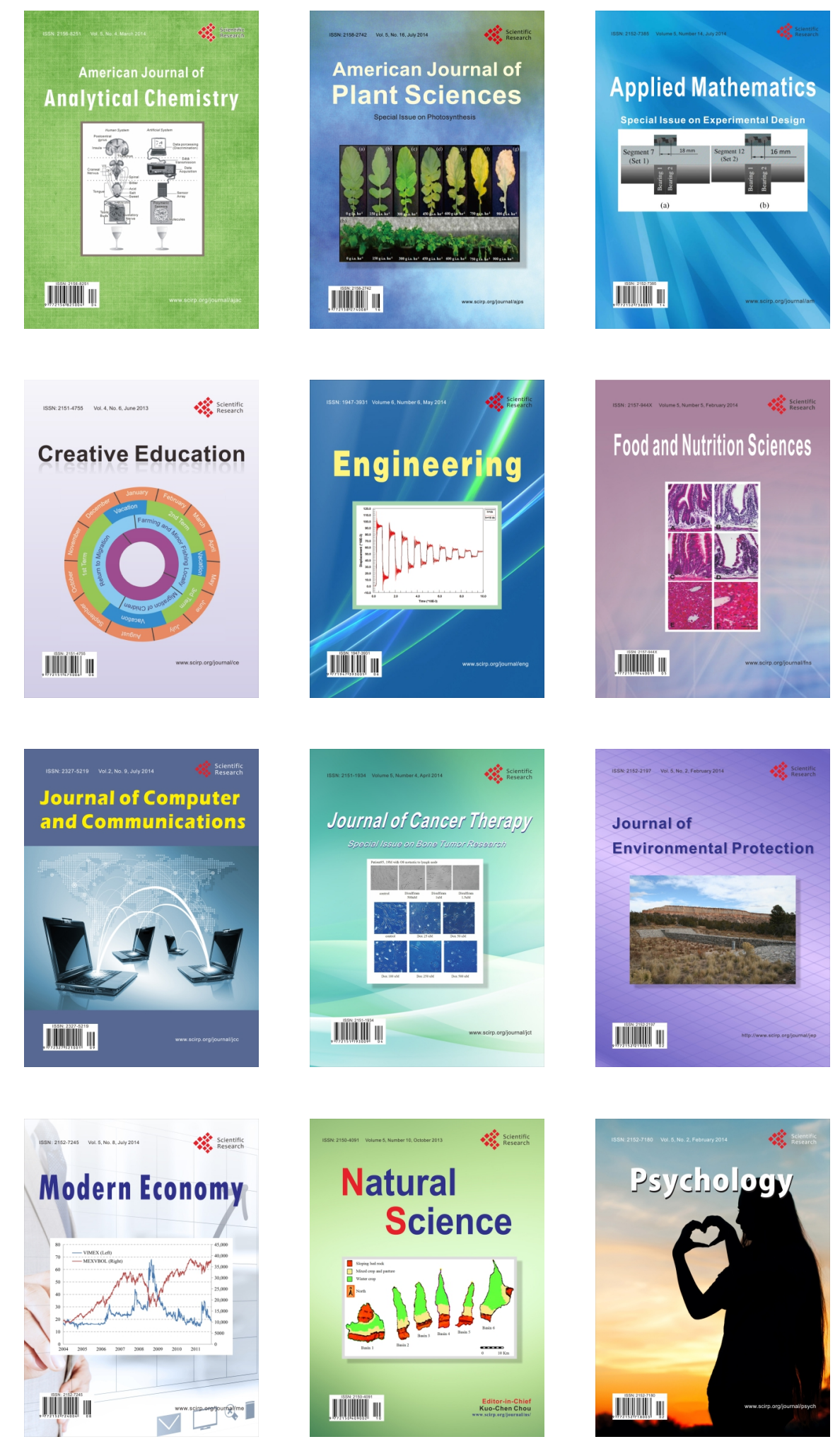